\title{
INVESTIGATION OF THE EFFECT OF ULTRASONIC WAVES ON THE ENHANCEMENT OF EFFICIENCY OF DIRECT PHOTOLYSIS AND PHOTOOXIDATION PROCESSES ON THE REMOVAL OF A MODEL CONTAMINANT FROM TEXTILE INDUSTRY
}

\author{
M.A. BEHNAJADY* \\ N. MODIRSHAHLA \\ M. SHOKRI \\ B. VAHID
}

Received: $28 / 10 / 07$

Accepted: 10/12/07

\author{
Department of Applied Chemistry \\ Islamic Azad University \\ Tabriz Branch \\ P.O. Box 1655, Tabriz, I.R. Iran
}

* to whom all correspondence should be addressed: Fax: 98411331392; e-mail: behnajady@iaut.ac.ir

\begin{abstract}
The effect of ultrasonic waves (US) was studied on the degradation of Malachite Green (MG) as a model contaminant from textile industry by direct photolysis with ultraviolet (UV) radiation and $\mathrm{UV} / \mathrm{H}_{2} \mathrm{O}_{2}$ processes. The US $(35 \mathrm{kHz})$ and UV $(253.7 \mathrm{~nm})$ radiations were carried out with an ultrasonic bath and a $15 \mathrm{~W}$ low-pressure mercury lamp, respectively. Degradation of MG follows pseudo-first order kinetics in all cases. The apparent reaction rate constant $\left(k_{a p}\right)$ for UV/US process is greater than sum of the UV and US processes but it is relatively low for practical uses. However $\mathrm{UV} / \mathrm{H}_{2} \mathrm{O}_{2}$ treatment more efficiently decomposes this organic contaminant and combining this process with US can improve its efficiency. $\mathrm{k}_{\mathrm{ap}}$ is influenced by variation of operational parameters such as power density, temperature, initial concentration of $M G$ and $\mathrm{H}_{2} \mathrm{O}_{2}$ for $\mathrm{US} / \mathrm{UV} / \mathrm{H}_{2} \mathrm{O}_{2}$ process and activation energy was $9 \mathrm{~kJ} \mathrm{~mol}^{-1}$ in the range of 294-307 $\mathrm{K}$ for this process. UV-vis spectral change of MG showed hypsochromic shift occurred with increasing sonication time, suggested $\mathrm{N}$-demethylation process of MG.
\end{abstract}

KEYWORDS: Advanced Oxidation Processes (AOPs), Hydroxyl radicals, US/UV/ $/ \mathrm{H}_{2} \mathrm{O}_{2}$, $\mathrm{UV} / \mathrm{H}_{2} \mathrm{O}_{2}$, UV/US.

\section{INTRODUCTION}

The textile industry's effluents are a major problem for the industries as well as a serious threat to the environment because $1-15 \%$ of the dyes are lost during dyeing process and cause environmental contamination due to their color and COD (Poon et al., 1999; Saure et al., 2002; Daneshvar et al., 2003). In general chemical and physical treatment processes, only transfer the contaminants from wastewater to other media and producing secondary wastes and leaving the problem essentially unsolved (Tanaka et al., 2000; Hachem et al., 2001). Advanced oxidation processes (AOPs) such as US (Adewuy, 2001; Ince and TezeanliGüyer, 2004), UV/ $\mathrm{H}_{2} \mathrm{O}_{2}$ (Behnajady et al., 2004), US/UV/ $\mathrm{H}_{2} \mathrm{O}_{2}$ (Poon et al., 1999; Fung et al., 2000), produce oxidizing species, generally hydroxyl radicals which are very powerful and unselectively oxidize organic compounds without causing secondary wastes.

Ultrasonic waves consist compression and rarefaction cycles. Cavitation is the origin of sonochemical effects and takes place in rarefaction cycles where negative acoustic pressure is enough to pull water molecules from each other to create tiny microbubbles (cavities). On the other hand in compression cycle of wave, acoustic pressure is positive. Finally microbubbles collapse violently during compression cycles and act as a localized microreactor which produces instantaneous temperatures of several thousand degrees and pressure in excess of one thousand atmospheres (Mason, 1999). In hot spot model three regions are postulated: (1) a hot gaseous nucleus, (2) an interfacial region (which is effective reaction site for unvolatile compounds (Okitsu et al., 2004)), (3) the bulk solution (Mason, 
1999; Adewuy, 2001). US process can degrade organic pollutants in aqueous solutions, (environmental sonochemistry (Adewuy, 2001; Vončina and Majcen-Le-Marechal, 2003)), by pyrolysis and free radical reactions involving ${ }^{\circ} \mathrm{OH}$ derived from decomposition of $\mathrm{H}_{2} \mathrm{O}$. The advantage of using US is based on simplicity of its use (Vinodgopal et al., 1998) but decomposition rates are still low for practical uses (Okitsu et al., 2004), therefore some techniques such as: (1) addition of solid particles (selli, 2002), (2) the combined use of $\mathrm{H}_{2} \mathrm{O}_{2}$ (Vončina and Majcen-Le-Marechal, 2003), and (3) the combined use of $\mathrm{UV} / \mathrm{H}_{2} \mathrm{O}_{2}$ (Poon et al., 1999), are coupled with US to enhance the reaction rate.

Direct photolysis reactions upon electronic excitation of the organic substrate imply in most cases an electron transfer from excited state to ground state molecular oxygen, with subsequent recombination of the radical ions or hydrolysis of the radical cation, or homolysis to form radicals which then react with oxygen. However the results demonstrate that $254 \mathrm{~nm}$ irradiation alone cannot be used as an effective procedure for the removal of organics from water (Legrini et al., 1993).

In $\mathrm{UV} / \mathrm{H}_{2} \mathrm{O}_{2}$ process when UV light is absorbed directly by $\mathrm{H}_{2} \mathrm{O}_{2}$, hydroxyl radicals are generated by photolysis of peroxide bond and the highest hydroxyl radical yields are obtained when short-wave ultraviolet radiations (200-280 nm) are used (Lopez et al., 2002).

The objectives of this study were to investigate the efficiency of different processes (UV, US, UV/US, US $/ \mathrm{H}_{2} \mathrm{O}_{2}, \mathrm{UV} / \mathrm{H}_{2} \mathrm{O}_{2}$ and US/UV/ $\mathrm{H}_{2} \mathrm{O}_{2}$ ) on the removal of $M G$ as a model contaminant from textile industry, in aqueous solution. Then the effect of operational parameters such as initial concentrations of $M G$ and $\mathrm{H}_{2} \mathrm{O}_{2}$, temperature and power density on the removal rate of $M G$ for US/UV/ $\mathrm{H}_{2} \mathrm{O}_{2}$ process which was the most effective method was studied.

\section{EXPERIMENTAL}

\subsection{Materials}

Malachite Oxalate Green, a triaryl cationic dye, was obtained from Panreac Co. (Espain) and used without further purification, as a model compound from textile dyes. Its chemical structure is given in figure 1 . The hydrogen peroxide solution $\left(30 \% \mathrm{w} / \mathrm{w}\right.$, with $\left.\rho=1.11 \mathrm{~g} \mathrm{ml}^{-1}\right)$ was purchased from Merck (Germany).

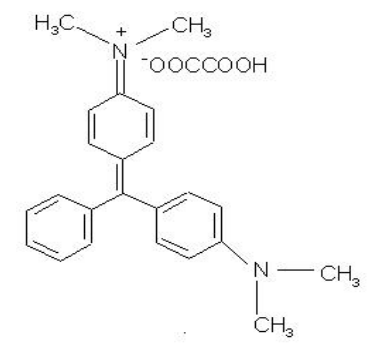

Figure 1. Chemical structure of MG

\subsection{Ultrasonic bath (T 460/H) and UV lamp}

The ultrasonic bath was purchased from Elma $(\mathrm{GmbH})$ with the operating frequency of $35 \mathrm{kHz}$ and with a rated output power of $170 \mathrm{~W}$. The bath had the dimension of $240 \times 137 \times 100 \mathrm{~mm}^{3}$. The efficiency of the bath was determined by calorimetric method (Mason, 1999) as $28.8 \%$ that indicates actual power dissipated in bulk solution is $49 \mathrm{~W}$. Power density is defined as actual power dissipated to the system divided to solution volume (Sivalcumar and Pandit, 2001). A low pressure mercury lamp ( $15 \mathrm{~W}$, UV-C, $\lambda_{\max }=254 \mathrm{~nm}$ manufactured by Philips, Holland) was placed above solution in the ultrasonic bath and light intensity at the solution surface was measured as $6 \mathrm{~W} \mathrm{~m}^{-2}$ with UV-Lux-IR meter (Leybold Co.). In order to maintain the temperature at desired value within $\pm 0.5 \mathrm{~K}$ a cooling coil was kept inside the reactor and water was pumped at the required pressure, on the other hand ultrasonic bath had an electrical heater in its back wall that could help to maintain the desired temperature. Mechanical stirrer was used in the solution with constant revolution per minute (150 r.p.m) because the effect of ultrasonic irradiation was enhanced with mechanical agitation (Mason, 1999; Okitsu et al., 2004). 


\subsection{Procedures}

In each experiment, certain volume of the MG solution with desired concentration was poured into ultrasonic bath and different initial concentrations of $\mathrm{H}_{2} \mathrm{O}_{2}$ were added to $\mathrm{MG}$ solution to prepare the reaction mixture. For comparison of the efficiency of different processes (UV, US, UV/US, US/ $/ \mathrm{H}_{2} \mathrm{O}_{2}, \mathrm{UV} / \mathrm{H}_{2} \mathrm{O}_{2}$ and US/UV/ $/ \mathrm{H}_{2} \mathrm{O}_{2}$ ) on the removal of $\mathrm{MG}$ from aqueous solution, experiments were carried out at the same experimental condition. In order to analyze MG concentration, at certain reaction intervals $5 \mathrm{ml}$ of sample was withdrawn and absorbance was determined by a UV-vis spectrophotometer (Ultrospec 2000, Biotech Pharmacia, England) at $617 \mathrm{~nm}$ and a calibration plot based on Beer-Lambert's law related the absorbance to concentration.

\section{RESULTS AND DISCUSSION}

3.1. Comparison between efficiency of different processes on the removal of MG Kinetics of degradation of MG is pseudo-first order in all processes. As shown in Table 1 in the same condition, the order of the efficiency of processes on the removal of $M G$ is:

$$
\mathrm{US} / \mathrm{UV} / \mathrm{H}_{2} \mathrm{O}_{2}>\mathrm{UV} / \mathrm{H}_{2} \mathrm{O}_{2}>\mathrm{US} / \mathrm{H}_{2} \mathrm{O}_{2}>\mathrm{UV} / \mathrm{US}>\mathrm{US}>\mathrm{UV}
$$

Table 1. Kinetic constants of six processes under the following experimental conditions

\begin{tabular}{cccc}
\hline Process & $\begin{array}{c}\mathrm{k}_{\mathrm{ap}} \\
\left(\mathrm{min}^{-1}\right)\end{array}$ & $\begin{array}{c}\text { Correlation coefficient } \\
\left(\mathrm{R}^{2}\right)\end{array}$ & $\begin{array}{c}\mathrm{t}_{1 / 2} \\
(\mathrm{~min})\end{array}$ \\
\hline $\mathrm{UV}$ & 0.0024 & 0.985 & 288.81 \\
$\mathrm{US}$ & 0.0103 & 0.998 & 67.30 \\
$\mathrm{US} / \mathrm{UV}$ & 0.0199 & 0.997 & 34.83 \\
$\mathrm{US} / \mathrm{H}_{2} \mathrm{O}_{2}$ & 0.0215 & 0.993 & 32.24 \\
$\mathrm{UV} / \mathrm{H}_{2} \mathrm{O}_{2}$ & 0.3079 & 0.990 & 2.25 \\
$\mathrm{US} / \mathrm{UV} / \mathrm{H}_{2} \mathrm{O}_{2}$ & 0.3556 & 0.998 & 1.95 \\
\hline
\end{tabular}

$[M G]_{0}=5 \mathrm{mg} \mathrm{l}^{-1},\left[\mathrm{H}_{2} \mathrm{O}_{2}\right]_{\mathrm{o}}=400 \mathrm{mg} \mathrm{l}^{-1}, \mathrm{PD}=0.049 \mathrm{~W} \mathrm{ml}^{-1}, \mathrm{~T}=294 \pm 0.5 \mathrm{~K}^{\mathrm{I}} \mathrm{I}_{\mathrm{o}}=6 \mathrm{~W} \mathrm{~m}^{-2}$

The combined effect of sonolysis and photolysis led to reaction rate constant $k_{U V+u s}$ which was greater than the sum of the reaction rate constants of sonolysis ( $k_{u s}$ ) and photolysis (kuv) employed separately. To easily compare the kinetic results obtained under different conditions, it is useful to define the synergy between US and UV processes in terms of first order rate constants:

$$
\text { Synergy }=\frac{k_{U S+U V}-\left(k_{U S}+k_{U V}\right)}{k_{U S+U V}}
$$

In this case synergy is 0.36 .

For $\mathrm{US} / \mathrm{UV} / \mathrm{H}_{2} \mathrm{O}_{2}$ process synergy is defined as:

$$
\text { Synergy }=\frac{\mathrm{k}_{\mathrm{US}+\mathrm{UV}+\mathrm{H}_{2} \mathrm{O}_{2}}-\left(\mathrm{k}_{\mathrm{US}+\mathrm{H}_{2} \mathrm{O}_{2}}+\mathrm{k}_{\mathrm{UV}+\mathrm{H}_{2} \mathrm{O}_{2}}\right)}{\mathrm{k}_{\mathrm{US}+\mathrm{UV}+\mathrm{H}_{2} \mathrm{O}_{2}}}
$$

In this case synergy is 0.074 .

Synergistic effects results show that ultrasonic waves enhance efficiency of UV process more than $\mathrm{UV} / \mathrm{H}_{2} \mathrm{O}_{2}$ process. Under sonolysis ${ }^{\circ} \mathrm{OH}$ and other radicals are generated from water scission because of implosion of cavitation bubbles and some of ${ }^{\circ} \mathrm{OH}$ radicals can combine and produce $\mathrm{H}_{2} \mathrm{O}_{2}$ which was accumulated during experiments (Selli, 2002; Manousaki et al., 2004). Therefore, the main effect of ultrasound is to contribute together with photolysis to the scission of $\mathrm{H}_{2} \mathrm{O}_{2}$, produced by sonolysis or $\mathrm{H}_{2} \mathrm{O}_{2}$ which was dissolved in solution in $U V / \mathrm{H}_{2} \mathrm{O}_{2}$ process. This effect is more significant for UV/US process because there was no hydrogen peroxide from the beginning of reaction and when sonolysis produce it, rapidly absorbe UV light and dissociate to produce extra ${ }^{\circ} \mathrm{OH}$ radicals when compared to US alone process. However $k_{a p}$ of US/UV/ $\mathrm{H}_{2} \mathrm{O}_{2}$ process is 17.87 times more than UV/US process which made it suitable for practical applications. 


\subsection{Effect of operational parameters on US/UV/ $\mathrm{H}_{2} \mathrm{O}_{2}$ process}

\subsubsection{The Effect of initial MG concentration}

The initial concentration of pollutant is important from an application view point. Hence the effect of initial MG concentration was investigated in the range of 2-10 $\mathrm{mg} \mathrm{l}^{-1}$ (Figure 2).

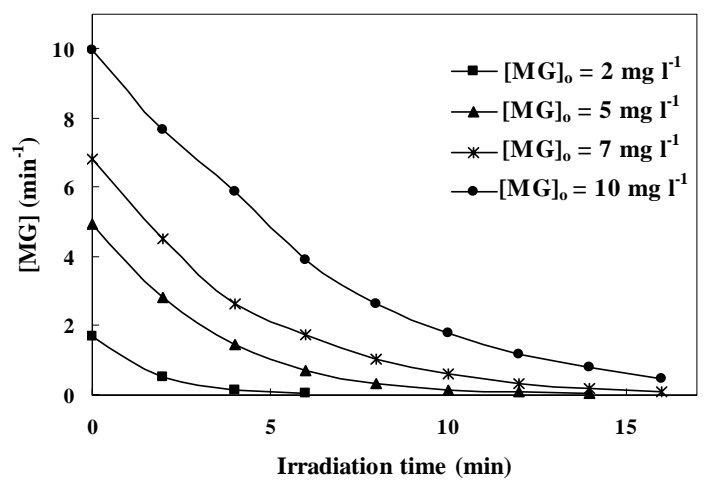

Figure 2. Effect of initial MG concentration on MG degradation.

$$
\begin{aligned}
{\left[\mathrm{H}_{2} \mathrm{O}_{2}\right]_{\mathrm{O}} } & =400 \mathrm{mg} \mathrm{l}^{-1}, \mathrm{PD}=0.049 \mathrm{~W} \mathrm{ml}^{-1}, \\
\mathrm{~T} & =294 \pm 0.5 \mathrm{~K}, \mathrm{I}_{\mathrm{o}}=6 \mathrm{~W} \mathrm{~m}^{-2}
\end{aligned}
$$

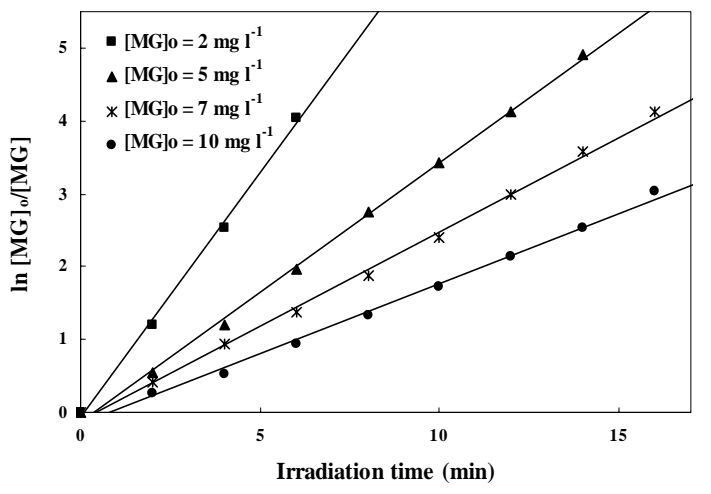

Figure 3. The semi-logarithmic plot of MG concentration versus irradiation time at different initial MG concentration (for experimental details refer to Figure 2)

Kinetics of the degradation of MG is pseudo-first order and simple mechanism is:

$\mathrm{MG}+{ }^{\bullet} \mathrm{OH} \rightarrow$ products

$-\frac{\mathrm{d}[\mathrm{MG}]}{\mathrm{dt}}=\mathrm{k}[\mathrm{MG}]\left[^{\bullet} \mathrm{OH}\right]$

as ${ }^{\bullet} \mathrm{OH}$ is very reactive and its concentration takes on a steady value during the process.

$\ln \frac{[\mathrm{MG}]}{[\mathrm{MG}]}=-\mathrm{k}_{\mathrm{ap}} \times \mathrm{t}$

$\mathrm{k}_{\mathrm{ap}}=\mathrm{k}\left[{ }^{\bullet} \mathrm{OH}\right]$

where $[M G]_{\circ}$ and $[M G]$ are initial concentration and concentration of $M G\left(\mathrm{mg} \mathrm{l}^{-1}\right)$ at time $t$, respectively. $k_{a p}$ and $t$ are pseudo-first order rate constant $\left(\mathrm{min}^{-1}\right)$ and irradiation time $(\mathrm{min})$, respectively.

The semi-logarithmic graphs of the concentration of MG for various initial concentrations of $M G$ versus irradiation time (Figure 3) yield straight lines, which confirm the proposed pseudofirst order kinetic for decolorization of $M G$ with $U S / U V / \mathrm{H}_{2} \mathrm{O}_{2}$ technique.

Figure 4 shows the plot of $k_{a p}$ vs. MG initial concentrations.

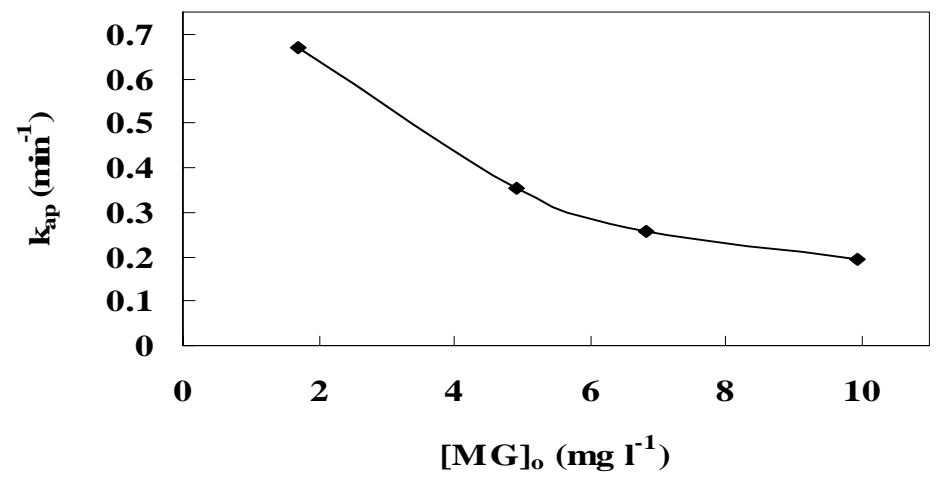

Figure 4. Pseudo-first order degradation rate constant of MG as a function of MG initial concentration (for experimental details refer to Figure 2) 
As shown in Figure 2 decolorization percent decreases with increasing initial concentration of MG at the same concentration of $\mathrm{H}_{2} \mathrm{O}_{2}$. This can be postulated by considering the high molar extinction coefficient of MG at $\lambda<260 \mathrm{~nm}$ and with increasing the initial MG concentration an inner filter is induced, hence the solution becomes more and more impermeable to UV radiation. On the other hand $M G$ is not a volatile compound and bubble-liquid interface is assumed as effective reaction site for US process, therefore MG decomposition may have been limited by available interface area (Manousaki et al., 2004). Both pyrolysis and free radical reactions can occur in the interfacial area but at low solute concentrations free radical reactions are predominant (Adewuy, 2001).

\subsubsection{The effect of initial $\mathrm{H}_{2} \mathrm{O}_{2}$ concentration}

The apparent reaction rate constants $\left(\mathrm{k}_{\mathrm{ap}}\right)$ for decolorization of MG using different amounts of $\mathrm{H}_{2} \mathrm{O}_{2}$ as obtained from semi-logarithmic graphs of MG concentrations versus time (Figure 5) are shown in Figure 6.

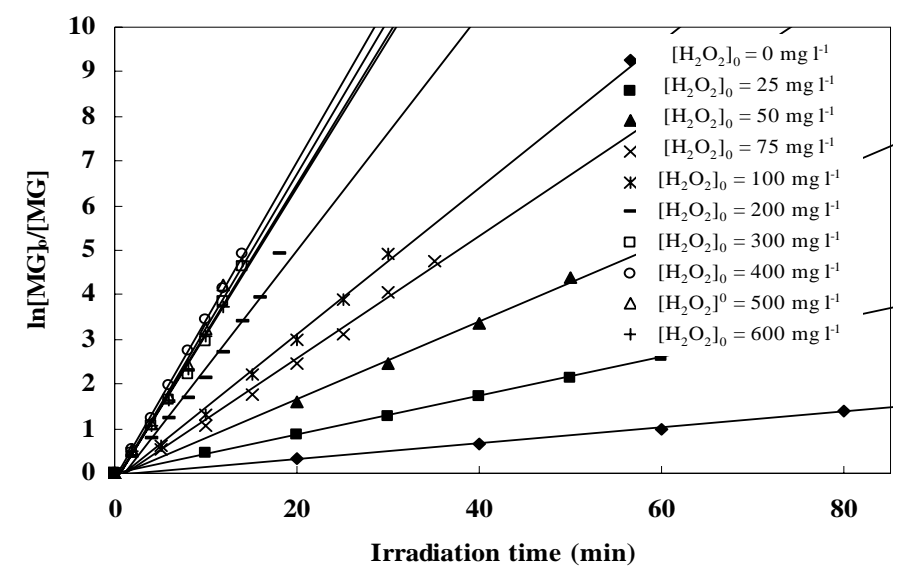

Figure 5. The semi-logarithmic plot of $M G$ concentration versus irradiation time at different initial $\mathrm{H}_{2} \mathrm{O}_{2}$ concentrations

$$
[M G]_{\circ}=5 \mathrm{mg} \mathrm{l}^{-1}, \mathrm{PD}=0.049 \mathrm{~W} \mathrm{ml}^{-1}, \mathrm{~T}=294 \pm 0.5 \mathrm{~K}, \mathrm{I}_{\mathrm{o}}=6 \mathrm{~W} \mathrm{~m}^{-2}
$$

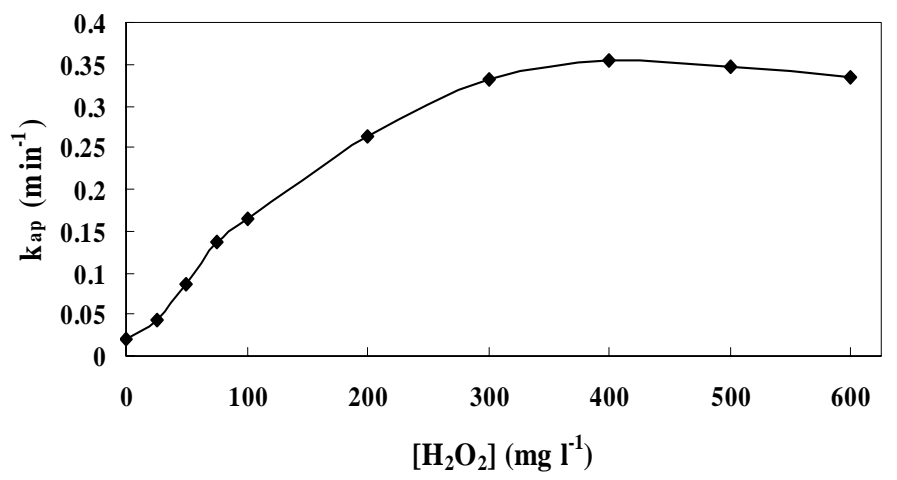

Figure 6. The plot of $\mathrm{k}_{\text {ap }}$ versus different initial concentrations of $\mathrm{H}_{2} \mathrm{O}_{2}$

(for experimental details refer to Figure 5).

As can be seen from figure 6 the removal efficiency increases with increasing $\mathrm{H}_{2} \mathrm{O}_{2}$ concentration to an optimum concentration of $400 \mathrm{mg} \mathrm{I}^{-1}$ and the additional $\mathrm{H}_{2} \mathrm{O}_{2}$ above optimum concentration causes to decrease $k_{a p}$. This occurrence can be explained by two opposite effects, with increasing $\mathrm{H}_{2} \mathrm{O}_{2}$ concentration:

1. more hydroxyl radicals are generated to attack aromatic rings and $\mathrm{k}_{\mathrm{ap}}$ increases.

2. above $400 \mathrm{mg} \mathrm{l}^{-1}, \mathrm{H}_{2} \mathrm{O}_{2}$ reacts with ${ }^{\circ} \mathrm{OH}$ competitively to form hydroperoxyl radicals. Since $\mathrm{HO}_{2}{ }^{\circ}$ radicals are not as reactive as ${ }^{\circ} \mathrm{OH}$, enhancement of them leads to a negligible contribution in MG destruction (Galindo et al., 2001). 
Fung et al. (2000) have also shown that the amount of degradation of $\mathrm{Cl}$ Reactive Red 120 dye increases with an addition of $\mathrm{H}_{2} \mathrm{O}_{2}$ until $66.6 \mathrm{mg} \mathrm{I}^{-1}$, on the other hand Poon et al. (1999) have reported the optimum concentration of $\mathrm{H}_{2} \mathrm{O}_{2}$ for degradation of cuprophenyl yellow $\mathrm{RL}$ as $33.3 \mathrm{mg} \mathrm{I}^{-1}$. The experimental condition of degradation of $\mathrm{Cl}$ Reactive Red 120 and cuprophenyl yellow RL are US transducers operating at $340 \mathrm{kHz}$ frequency and six low pressure mercury lamps as UV irradiation source with a power input of $11 \mathrm{~W}$ each, whereas in the present case, the frequency of operation was $35 \mathrm{kHz}$ and a power input of $6 \mathrm{~W} \mathrm{~m}^{-2}$ for UV light. Hence the rate as well as the number of formation of hydroxyl radicals will be much greater for the case of Fung et al. (2000) and Poon et al. (1999), because of more sever conditions as compared to this case, and hence the optimum concentration of hydrogen peroxide will be low. Paraga et al. (2002) have shown the sonophotochemical degradation of formic acid significantly increases in the presence of hydrogen peroxide and with an increase in the hydrogen peroxide loading in the range of $33.3-166.5 \mathrm{mg} \mathrm{I}^{-1}$, they have found no decrease in the extent of degradation, in this case, the frequency of operation was $20+30+50$ $\mathrm{kHz}$ and a power input of $8 \mathrm{~W}$ for UV light, also in this case the experimental condition was not as sever as Fung et al. (2000) and Poon et al. (1999), hence the optimum amount of $\mathrm{H}_{2} \mathrm{O}_{2}$ will be higher than their case. Finally we can conclude that optimum concentration of hydrogen peroxide depends on the type of pollutant and the condition of reaction.

\subsubsection{The effect of temperature}

Figure 7 shows that reaction rate enhances with increasing temperature from 294 to $307 \mathrm{~K}$. The Arrhenius equation can be definded as:

$$
-\ln k=-\ln A+\frac{E}{R}\left(\frac{1}{T}\right)
$$

where $\mathrm{k}=$ rate constant in $\mathrm{min}^{-1}, \mathrm{~T}=$ temperature in $\mathrm{K}$.

The activation energy value was $9 \mathrm{~kJ} \mathrm{~mol}^{-1}$ from Figure 7. Low activation energy, suggests that the sonochemical degradation is limited by diffusion step and apparent rate constant reflects the rate at which MG molecules diffuse from the bulk solution to the effective reaction zone (i.e., the solution-bubble interfacial region where temperature and hydroxcyl radical concentration are high). In addition, any increase in temperature will raise the vapor pressure of solution and so lead to easier cavitation but less violent collapse (Mason, 1999). At this temperature range, the effect of easier cavitation is predominant.

The activation energy for sonochemical decomposition of dibenzothiophene in aqueous solution was $12.6 \mathrm{~kJ} \mathrm{~mol}^{-1}$ in the temperature range of $288-323 \mathrm{~K}$, suggesting a diffusioncontrolled reaction (Kim et al., 2001).

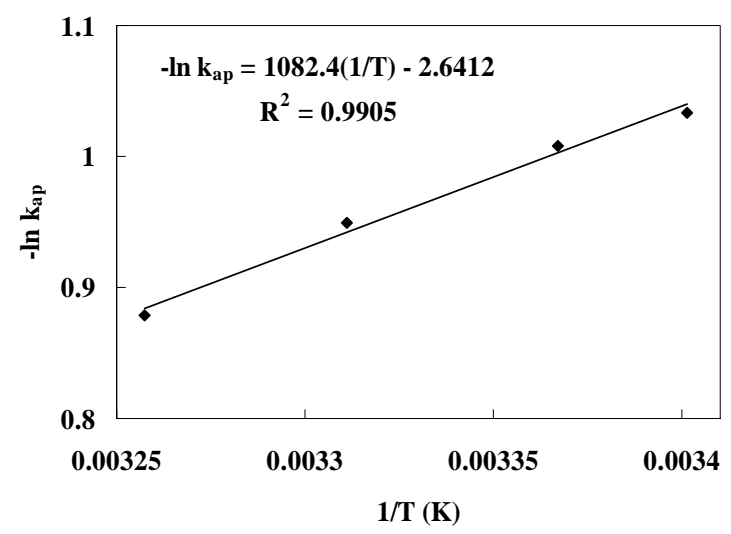

Figure 7. Effect of temperature on $\mathrm{k}_{\mathrm{ap}}$.

$[M G]_{0}=5 \mathrm{mg} \mathrm{l}^{-1},\left[\mathrm{H}_{2} \mathrm{O}_{2}\right]_{\mathrm{o}}=400 \mathrm{mg} \mathrm{l}^{-1}, \mathrm{PD}=0.049 \mathrm{~W} \mathrm{ml}^{-1}, \mathrm{I}_{\mathrm{o}}=6 \mathrm{~W} \mathrm{~m}^{-2}$.

\subsubsection{The Effect of power density}

Power density, $\left(\mathrm{W} \mathrm{ml}^{-1}\right)$, is the best factor to investigate optimization because directly gives an idea about actual power dissipated in the given volume of solution which depends on two 
factors in an ultrasonic bath: (1) the liquid height, and (2) liquid volume (Sivalcumar and Pandit, 2001). Therefore the effect of different volume of MG solution (300, 500, 700 and $1000 \mathrm{ml}$ ) which is correspondent to the power density from 0.049 to $1.163 \mathrm{~W} \mathrm{ml}^{-1}$ was investigated on the removal of MG.

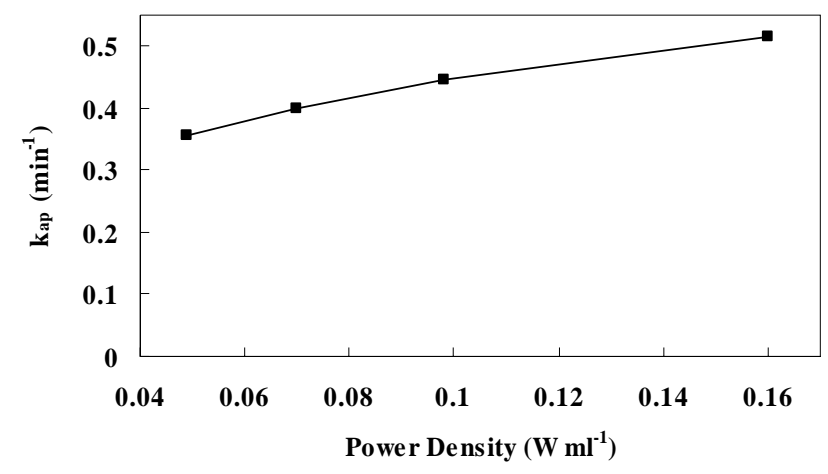

Figure 8. Effect of power density on $\mathrm{MG}$ sonochemical degradation. $[M G]_{0}=5 \mathrm{mg} \mathrm{l}^{-1},\left[\mathrm{H}_{2} \mathrm{O}_{2}\right]_{\mathrm{o}}=400 \mathrm{mg} \mathrm{l}^{-1}, \mathrm{~T}=294 \pm 0.5 \mathrm{~K}, \mathrm{I}_{\mathrm{o}}=6 \mathrm{~W} \mathrm{~m}^{-2}$

As shown in figure $8 \mathrm{k}_{\mathrm{ap}}$ increases with increasing the power density. In this case, it is due to higher energy dissipated to the system with decreasing volume at the same energy input. Sivalcumar and pandit (2001) have shown the degradation of Rhodamin B, using ultrasonic bath has an optimum value of $0.063 \mathrm{~W} \mathrm{ml}^{-1}$.

\subsection{Spectral changes of MG during degradation}

The changes in absorption spectra of MG during irradiation at 2 min intervals were shown in figure 9. It is interesting that absorption of the visible band at $617 \mathrm{~nm}$ decreased and a hypsochromic shift occurred simultaneously with increasing time. The maximum absorption wavelength shifts from 617 to $598 \mathrm{~nm}$ at $12 \mathrm{~min}$ of irradiation time. The hypsochromic shift process is an $\mathrm{N}$-demethylation process (Huang et al., 2001). In addition formation of benzophenone derivatives, $p$-aminobenzoic acid and aniline as intermediate reaction products resulted from reaction of a triphenylmethane dye with hydroxyl radicals were detected (Saquib and Muneer, 2003). Therefore it is concluded that the degradation of MG occurs via two competitive processes: $\mathrm{N}$-demethylation and destruction of the conjugated structure.

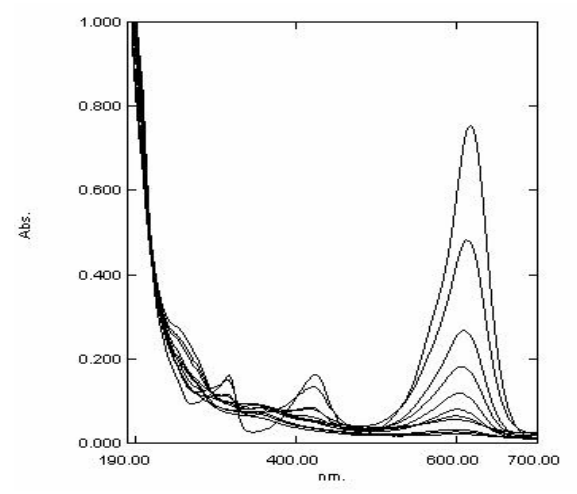

Figure 9. UV-vis spectral changes of MG, recorded during

the dye degradation at 2 min sonication intervals.
$[\mathrm{MG}]_{\mathrm{o}}=5 \mathrm{mg} \mathrm{l}^{-1},\left[\mathrm{H}_{2} \mathrm{O}_{2}\right]_{\mathrm{o}}=400 \mathrm{mg} \mathrm{l}^{-1}, \mathrm{PD}=0.049 \mathrm{~W} \mathrm{ml}^{-1}, \mathrm{~T}=294 \pm 0.5 \mathrm{~K}, \mathrm{I}_{\mathrm{o}}=6 \mathrm{~W} \mathrm{~m}^{-2}$.

\section{CONCLUSIONS}

US/UV/ $/ \mathrm{H}_{2} \mathrm{O}_{2}$ was the most effective process for degradation of $M G$ from aqueous solution and its $\mathrm{k}_{\mathrm{ap}}$ is 1.15 times more than $\mathrm{UV} / \mathrm{H}_{2} \mathrm{O}_{2}$ process. $\mathrm{k}_{\mathrm{ap}}$ for UV/US process was 1.93 and 8.29 times more than US and UV processes but it is relatively low for practical uses. The removal rate of $M G$ follows pseudo-first order kinetics in all cases. $k_{a p}$ increases with increasing temperature, power density and decreasing initial concentration of MG. The 
activation energy of reaction in temperature range of 294-307 K was $9 \mathrm{~kJ} \mathrm{~mol}^{-1}$ for US/UV/ $\mathrm{H}_{2} \mathrm{O}_{2}$ process and optimum concentration of hydrogen peroxide in this process was $400 \mathrm{mg} \mathrm{l}^{-1}$. Hypsochromic shift in UV-vis spectrum indicates $\mathrm{N}$-demethylation product is one of the intermediates during irradiation.

\section{REFERENCES}

Adewuy Y.G. (2001) Sonochemistry: environmental science and engineering applications, Ind. Eng. Chem. Res., 40, 4681-4715.

Behnajady M.A., Modirshahla N. and Shokri M. (2004) Photodestruction of Acid Orange 7 (AO7) in aqueous solutions by $\mathrm{UV} / \mathrm{H}_{2} \mathrm{O}_{2}$ : influence of operational parameters, Chemosphere, 55, 129134.

Bruan A.M., Oliveros E. and Legrini O. (1993) Photochemical Processes for Water Treatment, Chem. Rev., 93, 671-698.

Daneshvar N., Ashassi-Sorkhabi H. and Tizpar A. (2003) Decolorization of orange II by electro coagulation method, Sep. Purif. Technol., 31, 153-162.

Fung P.C., Sin K.M., Tsui S.M. and Poon C.S. (1999) Treatability study of organic and color removal an desizing/dyening wastewater by UV/US system combined with hydrogen peroxide, Water Sci. Technol., 40, 153-159.

Galindo C., Jacques P. and Kalt A. (2001) Photochemical and photocatalytic degradation of an indigoid dye: a case study of acid blue 74, J. Photochem. Photobiol. A, 141, 47-56.

Hachem C., Boequillon F., Zahraa O. and Bouchy M. (2001) Decolourization of textile industry wastewater by photocatalytic degradation process, Dyes Pigments, 49, 117-125.

Huang C.P., Chiu P.C. and Kim J.K. (2001) Sonochemical Decomposition of dibenzothiophene in aqueous solution, Water Res., 35, 4370-4378.

Ince N.H. and Tezeanli-Güyer G. (2004) Impacts of pH and molecular structure on ultrasonic degradation of azo dyes, Ultrasonics Sonochem., 42, 591-596.

Kim J.K., Huang C.P. and Chiu P.C. (2001) Sonochemical Decomposition of dibenzothiophene in aqueous solution, Water Res., 35, 4370-4378.

Lopez A., Bozzy A., Mascolo G. and Kiwi J. (2003) Kinetic investigation on UV and $U V / \mathrm{H}_{2} \mathrm{O}_{2}$ degradations of pharmaceutical intermediates in aqueous solution, J. Photochem. Photobiol. A, 156, 121-126.

Manousaki E., Psillakis E., Kalogerakis N. and Mantzavinos D. (2004) Degradation of sodium dodecylbenzene sulfonate in water by ultrasonic irradiation, Water Res., 38, 3751-3759.

Mason T.J. (1999) Sonochemistry, First Edition, Oxford Science Publications, New York, USA.

Okitsu K., Iwasaki K., Yobiko Y., Bandow H., Nishimura R. and Maeda Y. (2005) Sonochemical degradation of azo dyes in aqueous solution: a new heterogeneous kinetics model taking into account the local concentration of $\mathrm{OH}$ radicals and azo dyes, Ultrasonics Sonochem., 12, 255262.

Parag R.G., Mujumdar S. and Pandit A.B. (2002) A sonophotochemical reactor for the removal of formic acid from wastewater, Ind. Eng. Chem. Res., 41, 3370-3378.

Poon C.S., Huang Q. and Fung P.C. (1999) Degradation kinetics of cuprophenyl yellow RLby $\mathrm{UV} / \mathrm{H}_{2} \mathrm{O}_{2} /$ Ultrasonication (US) Process in Aqueous Solution, Chemosphere, 38, 1005-1014.

Saquib M. and Muneer M. (2003) $\mathrm{TiO}_{2}$-mediated photocatalytic degradation pf triphenylmethane dye (gentian violet), in aqueous suspensions, Dyes Pigments, 56, 37-49.

Sauer T., Neto G.C., Jose H.J. and Moreira R.F.P.M. (2002) Kinetics of photocatalytic degradation of reactive dyes in a $\mathrm{TiO}_{2}$ slurry reactor, J. Photochem. Photobiol. A, 149, 147-154.

Selli E. (2002) Synergistic effects of Sonolysis combined with photocatalysis in the degradation of an azo dye, Phys. Chem. Chem. Phys., 4, 6123-6128.

Sivalcumar M. and Pandit A.B. (2001) Ultrasound enhanced degradation of Rhodmine B: Optimization with power density, Ultrason. Sonochem., 8, 233-240.

Tanaka K., Padermpole K. and Hisanage T. (2000) Photocatalytic degradation of commercial azo dyes, Water Res., 34, 327-333.

Vončina D.B. and Majcen-Le-Marechal A. (2003) Reactive dye decolorization using combined ultrasound/ $\mathrm{H}_{2} \mathrm{O}_{2}$, Dyes Pigments, 59, 173-179.

Vinodgopal K., Peller J., Makogon O. and Kamat P.V. (1998) Ultrasonic mineralization of reactive, textile azo dye, Remazol Black B, Water Res., 32, 3646-3650. 